\title{
Acute Pancreatitis
}

National Cancer Institute

\section{Source}

National Cancer Institute. Acute Pancreatitis. NCI Thesaurus. Code C95437.

An acute inflammatory process that leads to necrosis of the pancreatic parenchyma.

Signs and symptoms include severe abdominal pain, nausea, vomiting, diarrhea, fever, and shock. Causes include alcohol consumption, presence of gallstones, trauma, and drugs. 